\title{
Safety of treatment for subclinical osteomalacia in the elderly
}

\author{
D J HOSKING, G A CAMPBELL, J R KEMM, R E COTTON, R V BOYD
}

\begin{abstract}
Forty one elderly patients admitted to hospital for acute illnesses were also found to have subclinical osteomalacia. Immediately before discharge, therefore, all were randomised to receive either vitamin $D_{2} 25 \mu \mathrm{g}$ daily, alfacalcidol $0.5 \mu \mathrm{g}$ daily, or placebo. Treatment was given for at least three months, those allocated to placebo then being switched to an active drug.

Within the first three months of treatment with either of the active drugs most patients had exhibited a fall to normal in osteoid values. In only four treatment periods was there a mild increase in serum calcium concentration, and in no patient was this accompanied by deterioration in renal function. Any increase in serum creatinine concentration was invariably attributable to the underlying disease for which the patient had been admitted in the first place.

Subclinical osteomalacia in the elderly may be corrected by relatively low doses of alfacalcidol $(0.5 \mu \mathrm{g}$ daily) or vitamin $D_{2}(25 \mu g$ daily) given for three months. Such treatment is safe and not accompanied by a serious risk of hypercalcaemia or renal impairment.
\end{abstract} Department of Medicine, Queen's Medical Centre, Nottingham
NG7 2UH

D J HOSKING, MD, FRCP, senior lecturer in medicine

Department of Community Health, Queen's Medical Centre, Nottingham NG7 2UH

J R KEMM, MD, MRCP, lecturer in community health

Department of Health Care of the Elderly, Sherwood Hospital, Nottingham

G A CAMPBELL, BSC, MRCP, research fellow

R V BOYD, FRCP, consultant geriatrician

Department of Pathology, City Hospital, Nottingham

R E COTTON, MD, FRCPATH, special professor of diagnostic oncology

Correspondence to: Dr D J Hosking.

\section{Introduction}

Vitamin D deficiency is a common problem in the elderly, ${ }^{1-4}$ although it may be difficult to recognise on purely clinical grounds $^{5}$ (J R Kemm et al, paper submitted for publication). As the first sign may be fracture of a femoral neck ${ }^{6}$ one option is to screen at risk populations for abnormality in order to offer prophylactic treatment. If, however, patients without symptoms are to be treated in the expectation of future benefit then it is essential to show that this course of action is without risk.

A survey of the prevalence of vitamin D deficiency in an acutely ill hospital population ${ }^{4}$ identified several cases of subclinical osteomalacia. This provided an opportunity to assess the safety of treatment and to compare the therapeutic efficacy of vitamin $\mathrm{D}_{2}$ with that of alfacalcidol. This second preparation was chosen because renal impairment is common in this type of patient ( $\mathrm{J} \mathrm{R} \mathrm{Kemm} \mathrm{et} \mathrm{al,} \mathrm{paper} \mathrm{submitted} \mathrm{for}$ publication) and, unlike vitamin $\mathrm{D}$, it does not require renal $1 \alpha$-hydroxylation for biochemical activity. The effect of treatment on the histological components of vitamin D deficiency is described elsewhere, ${ }^{7}$ and the present paper considers only the safety of this intervention.

\section{Patients and methods}

The screening programme (J R Kemm et al, paper submitted for publication) based on fasting measurements of serum calcium, phosphate, and alkaline phosphatase on the morning after admission to hospital identified 41 patients with varying combinations of biochemical abnormality suggestive of vitamin $\mathrm{D}$ deficiency. An 8 gauge Jamshidi needle biopsy of the iliac crest was performed in all these patients and the amount of osteoid quantified by a semiautomatic (Videoplan) system. ${ }^{8}$ Immediately before discharge from hospital the 41 patients were randomised to treatment with either vitamin $\mathrm{D}_{2}$ (25 $\mu \mathrm{g}$ daily), alfacalcidol ( $0.5 \mu \mathrm{g}$ daily), or placebo. Those given placebo were reallocated to active drug after three months.

Serum calcium, phosphate, creatinine, and alkaline phosphatase values were measured monthly during treatment using standard laboratory techniques ${ }^{8}$ and the iliac crest biopsies were repeated every three months. Treatment was withdrawn once osteoid dis- 
appeared from the biopsy sample or reached a stable minimum value. Serum calcium concentration was corrected to the mean serum albumin value of the hospital population $(30 \mathrm{~g} / \mathrm{l})$ using a factor of $0.015 \mathrm{mmol}$ calcium per litre $(0.06 \mathrm{mg} / 100 \mathrm{ml}) / \mathrm{g}$ albumin derived by regression analysis of our population data. (J R Kemm et al, paper submitted for publication.)

\section{Results}

All the patients received active drug for at least three months; 10 patients given alfacalcidol and 16 given vitamin $\mathrm{D}$ were treated for an additional three months.

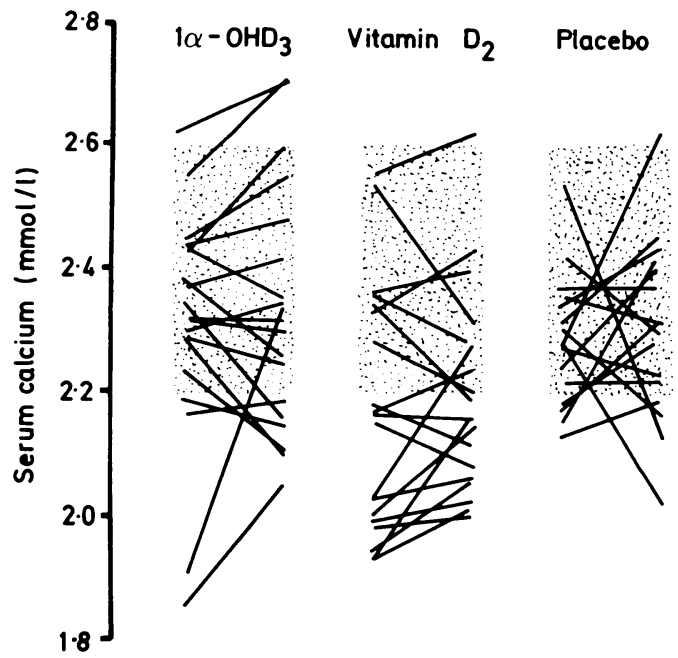

FIG 1-Changes in serum calcium concentrations after three months' treatment with alfacalcidol $\left(1 \alpha-\mathrm{OHD}_{3}\right)$ and vitamin $\mathrm{D}_{2}$. Normal ranges shown as shaded areas.

Conversion: SI to traditional units-Calcium: $1 \mathrm{mmol} / 1 \approx$ $4 \mathrm{mg} / 100 \mathrm{ml}$.

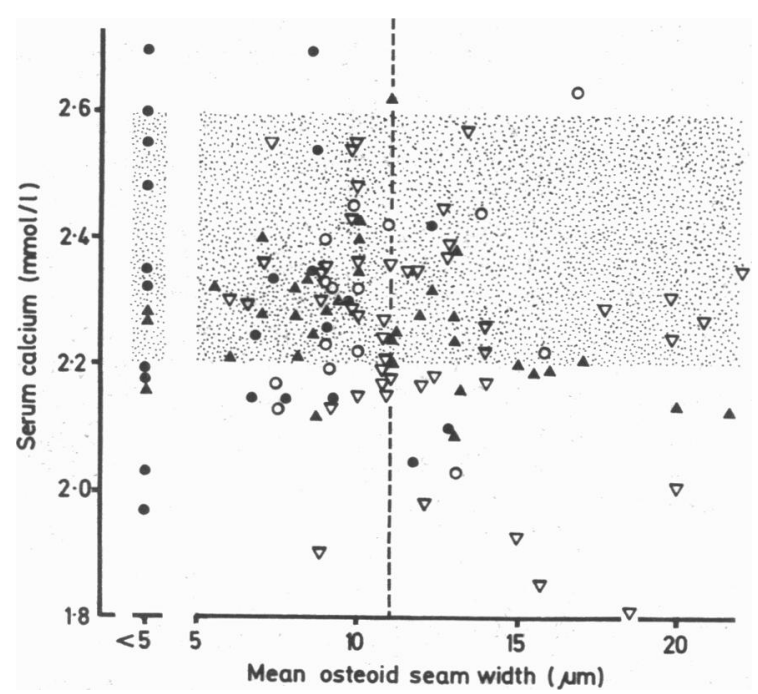

FIG 2-Relation between serum calcium concentration and osteoid seam width before and during treatment. $\nabla=$ Basal measurements. $O=$ Placebo. $O=$ Alfacalcidol. $\boldsymbol{\Delta}=$ Vitamin $\mathrm{D}_{2}$ - - - = Lower limit of reference range. ${ }^{8}$

Conversion: SI to traditional units-Calcium: $1 \mathrm{mmol} / 1 \approx 4 \mathrm{mg}$ / $100 \mathrm{ml}$.

The maximum decrease in the amount of osteoid usually occurred within the first three months of treatment, by which time most values lay within the reference range for these measurements. ${ }^{7}$

Hypercalcaemia was an uncommon problem with the doses of vitamin $D_{2}$ and alfacalcidol used in the study. Figure 1 shows the serum calcium concentrations before and after the first three months of treatment. Of the 56 treatment periods, only four were accompanied by a mild increase in the serum calcium value (to $2 \cdot 6-2 \cdot 7 \mathrm{mmol} / 1$ $(10.4-10.8 \mathrm{mg} / 100 \mathrm{ml})$ ). One patient, however, was hypercalcaemic before treatment and remained so throughout. In the remaining patients the mild hypercalcaemia found at three months was an isolated event, subsequent measurements giving values within the normal range. There was no tendency of the serum calcium concentration to rise with time. In 10 patients treated with alfacalcidol the mean serum calcium concentrations at zero, three, and six months were 2.31 (SD 0.17$), 2.38(0.19)$, and $2.25(0.20) \mathrm{mmol} / 1$ respectively (9.24 (SD 0.68), $9.52(0.76)$, and $9.00(0.80) \mathrm{mg} / 100 \mathrm{ml})$. Comparable values for 16 patients treated with vitamin $\mathrm{D}_{2}$ were $2 \cdot 27$ (SD $0 \cdot 16$ ), $2.28(0.12)$, and $2.33(0.13) \mathrm{mmol} / 1(9.08(\mathrm{SD} 0.64), 9.12(0.48)$, and $9.32(0.52) \mathrm{mg} / 100 \mathrm{ml})$.

In order to determine whether the presence of osteoid protects against vitamin $\mathrm{D}$ induced hypercalcaemia the concentration of serum calcium and the mean osteoid seam width were compared before and after three months' treatment (fig 2). The findings showed no correlation between these variables, and-particularly importantminor amounts of osteoid were not associated with an increased risk of hypercalcaemia.

None of the episodes of hypercalcaemia were accompanied by evidence of a deterioration in renal function. Although four patients treated with alfacalcidol or vitamin $\mathrm{D}_{2}$ showed a rise in serum creatinine concentration (fig 3 ), this invariably reflected progression of the underlying disease for which they had originally been admitted to hospital.

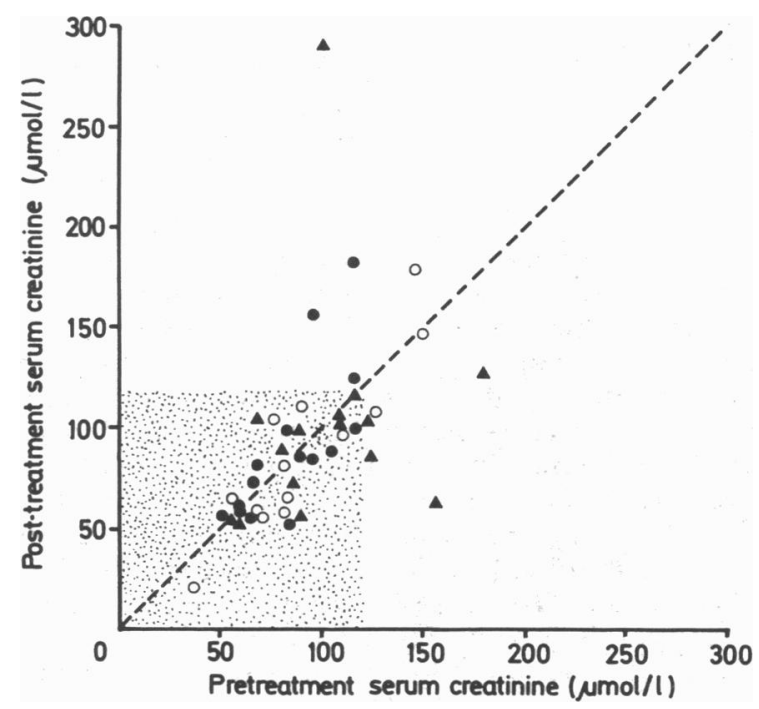

FIG 3-Serum creatinine concentrations before and after treatment. $\quad=$ Alfacalcidol. $\quad \boldsymbol{\Delta}=$ Vitamin $\mathrm{D}_{2} . \quad \mathrm{O}=$ Placebo. - . - - = Line of identity.

Conversion: SI to traditional units-Creatinine: $1 \mu \mathrm{mol} / 1 \approx$ $0.01 \mathrm{mg} / 100 \mathrm{ml}$.

\section{Discussion}

If treatment of subclinical osteomalacia in the elderly is to gain general acceptance then it is essential to know that it is both safe and effective. We have already shown that the second of these objectives may be achieved by a relatively short three month course of replacement therapy. ${ }^{7}$ The safety of this type of treatment, however, particularly with respect to the risk of developing hypercalcaemia or renal impairment, depends on several factors.

Vitamin $\mathrm{D}_{2}$ in the dose used here ( $25 \mu \mathrm{g}$ daily) has inherent safety because both the hepatic and renal hydroxylations which are needed to achieve full biological potency are carefully regulated in vivo. ${ }^{9}$ Unfortunately, renal impairment was a common feature of the elderly hospital population studied (J R Kemm et al, paper submitted for publication), and this type of patient tends to respond poorly to vitamin $\mathrm{D}_{2}$. The requirement for renal hydroxylation may be avoided by the use of alfacalcidol, ${ }^{9}$ but since the regulatory mechanisms which 
protect against toxicity are bypassed doubt has been expressed about its safety in the elderly. ${ }^{10}$ Our study, however, shows that in the dose needed to heal subclinical osteomalacia $(0.5 \mu \mathrm{g}$ daily) ${ }^{7}$ alfacalcidol proved free from the risk of hypercalcaemia. Although there were four episodes of hypercalcaemia, the circumstances under which this occurred suggested that it was not due to vitamin $\mathrm{D}$ intoxication. Moreover, none of the episodes was accompanied by a deterioration in renal function. In this type of study it is very difficult to separate the effects of treatment on renal function from those of unrelated systemic disease. In the few instances of an increase in serum creatinine concentration this appeared to be due to progression of the underlying illness which had precipitated the patients' original hospital admission rather than to a side effect of treatment. ${ }^{11}$

Experience with renal osteodystrophy has shown that although hypercalcaemia may appear in the early stages of treatment, it may also develop for the first time when the osteomalacia has almost healed. ${ }^{12}{ }^{13}$ This is a reflection of skeletal uptake of calcium as osteoid remineralises which offsets any tendency of calcium absorption, stimulated by treatment, to cause hypercalcaemia. This buffering capacity, however, is progressively lost as the bone disease heals. Hence there was some anxiety that the small excess of osteoid in the elderly patients in this series would be insufficient to protect them against hypercalcaemia. Fortunately, it is clear that the posttreatment serum calcium concentration is not critically dependent on the presence or extent of trabecular osteoid. The safety of the present regimen is probably a function of dose, since patients with hypoparathyroidism ${ }^{14}$ or osteoporosis ${ }^{15}$ (who also do not have an excess of osteoid) may become hypercalcaemic when treated with larger doses of alfacalcidol or calcitriol.

GAC was supported by the research committee of the Trent Regional Health Authority.

\section{References}

1 Anderson I, Campbell AER, Dunn A, Runciman JBM. Osteomalacia in elderly women. Scott Med f 1966;2:429-35.

Chalmers J, Conacher WDH, Gardner DL, Scott PJ. Osteomalacia: a common disease

, Vitamin D status in long stay geriatric patients. Lancet 1975 ; $\mathrm{i}$ : 1404-6.

long stay geriatric patients. Lancet $1975 ; 1: 1404-6$. in the elderly? Lancet (in press).

5 Exton-Smith AN. Nutrition of the elderly. Br f Hosp Med 1971;5:639-46.

6 Aaron JE, Gallagher JC, Anderson J, et al. Frequency of osteomalacia and osteoporosis in fracture of the proximal femur. Lancet $1974 ; \mathrm{i}: 229-33$.

7 Hosking DJ, Campbell GA, Kemm JR, et al. Screening for subclinical osteomalacia in the elderly-normal ranges or pragmatism? Lancet 1983 ;ii: $1290-2$

$8 \mathrm{Kemm}$ JR, Campbell GA, Cotton RE, Hosking DJ, Boyd RV. Osteoid in bones of elderly patients without bone disease. Age Ageing 1984;13:144-51.

9 De Luca HF. Vitamin D. Metabolism and function. Berlin: Springer Verlag, 1979. 10 Parfitt AM. Screening for vitamin D depletion. Lancet $1984 ; \mathrm{i}: 227-8$.

Massry SG, Goldstein DA. Is calcitriol $\left(1,25(\mathrm{OH})_{2} \mathrm{D}_{3}\right)$ harmful to renal function ? 3AMA $1979 ; 242: 1875-6$

(In Lawson DEM, ed. Vitamin D. London: Academic Press, 1978:303-86.

作 作 $\mathrm{D}_{3}$ and 1,25 dihydroxy vitamin $\mathrm{D}_{3}$ on calcium and phosphorus metabolism in hypoparathyroidism. Metabolism 1975;24:1403-13.

15 Sorensen OH, Andersen RB, Christensen MS, et al. Treatment of senile osteoporosis with $1 \alpha$-hydroxy-vitamin $\mathrm{D}_{3}$. Clin Endocrinol (Oxf) 1977;7 (suppl):169-75s.

(Accepted 27 fune 1984)

\title{
Effect of an oral serotonin antagonist, ketanserin, on plasma ACTH concentrations in Nelson's syndrome
}

\author{
R W G PRESCOTT, W A RATCLIFFE, P KENDALL TAYLOR
}

\begin{abstract}
A study was performed to see whether ketanserin, a serotonin antagonist, would reduce the raised concentrations of adrenocorticotrophic hormone (ACTH) in patients with Nelson's syndrome. Six patients who had undergone bilateral adrenalectomy for Cushing's disease and who had Nelson's syndrome were given ketanserin $40 \mathrm{mg}$ twice daily and placebo, for at least two months each, in a double blind crossover study. Ketanserin had no effect on ACTH concentrations.

In healthy people serotonin seems to have a stimulatory role in the regulation of ACTH secretion, and the effect of ketanserin in reducing the ACTH response to hypoglycaemia suggested that it might prove useful in Nelson's syndrome. These results show that it is not indicated in these patients.
\end{abstract}

\footnotetext{
Department of Medicine (Geriatrics), Newcastle General Hospital, Newcastle upon Tyne

$\mathrm{R}$ W G PRESCOTT, $M D, M R C P$, first assistant in medicine (geriatrics)

Department of Chemical Pathology, Hope Hospital, Salford W A RATCLIFFE, BSC, PHD, senior biochemist

Department of Medicine, Royal Victoria Infirmary, Newcastle upon Tyne

P KENDALL TAYLOR, MD, FRCP, reader in endocrinology

Correspondence to: Dr P Kendall Taylor.
}

\section{Introduction}

Nelson's syndrome, characterised by increased skin pigmentation and high circulating adrenocorticotrophic hormone (ACTH) concentrations, results from the development of an ACTH secreting pituitary adenoma after bilateral adrenalectomy for Cushing's disease. Once it has developed the adenoma can be locally invasive and difficult to control by either irradiation or hypophysectomy. Hence there is a need for effective drug treatment, and drugs which may alter the neurotransmitter control of ACTH have been tried in this condition. ${ }^{12}$ Serotonin influences the release of corticotrophin releasing factor, and the relatively weak and non-specific antiserotonin agent cyproheptadine is sometimes useful in Cushing's disease or Nelson's syndrome. ${ }^{2}$ Ketanserin is a new and specific serotonin antagonist, and the present double blind study was therefore designed to evaluate its effect on the ACTH concentrations of patients with Nelson's syndrome.

\section{Patients and methods}

Five women and one man aged 36-65 years were studied. All had undergone bilateral adrenalectomy for Cushing's disease five to 23 years previously. The pituitary fossa was enlarged in two patients. Three patients had received external irradiation to the pituitary six to 17 years previously. Characteristic increased pigmentation was present in five patients, and in the sixth pigmentation had resolved after external irradiation, although plasma ACTH concentrations remained raised. All patients were receiving hydrocortisone replace- 